\title{
Perancangan Katalog Museum Keraton Sumenep dengan Konsep Budaya Lahir Melalui Sejarah
}

\author{
Yusticia Elrachmaditha Sukarto dan Denny Indrayana Setyadi \\ Departemen Desain Produk Industri, Institut Teknologi Sepuluh Nopember (ITS) \\ e-mail: dennyindrayanasetyadi@gmail.com
}

\begin{abstract}
Abstrak - Keraton Sumenep adalah salah satu cagar budaya yang memiliki nilai sejarah yang mendasari terbentuknya identitas budaya Sumenep. Nilai sejarah dan budaya Keraton Sumenep lebih banyak disebarkan melalui mulut ke mulut yang berdampak kepunahan sehingga perlu dilestarikan secara tertulis agar informasi dapat dijaga dan diteruskan oleh generasi berikutnya. Tujuan perancangan katalog ini merepresentasikan identitas budaya Sumenep sebagai daerah Keraton sebagai bentuk pelestarian sejarah dan budaya. Metode yang digunakann dalam penelitian ini adalah metode deskriptif dengan pendekatan kualitatif melalui depth interview pada pakar sejarah Sumenep, pihak museum, dan Disbudparpora Sumenep. Depth interview juga dilakukan dengan ahli editorial dan fotografi dari Akronim Studio. Pengumpulan data dilakukan melalui observasi berkala dan studi eksperimenntal dengan mengunjungi Keraton Sumenep untuk mendapatkan data visual dan berdiskusi dalam menyusun data konten bersama pakar sejarah. Sebagai data sekunder, dilakukan pula kajian pustaka terhadap buku yang berkaitan dengan sejarah budaya Keraton Sumenep. Konsep yang ditawarkan peneliti dalam menyusun katalog adalah "Budaya Lahir Melalui Sejarah", berarti budaya yang ada saat ini adalah cerminan sejarah masa lampau. Hasil perancangan ini adalah buku katalog berisi 124 benda museum dengan susunan foto, ukuran, bahan, dan penejelasan tentang benda museum. Dalam katalog berisi 7 bangunan inti museum yang dijelaskan dengan pembabakan. Pembabakan dibagi menjadi 8 yaitu sejarah Keraton Sumenep, Labang Mesem, Halaman Keraton, Pendopo Agung, Mandiyoso \& R.Tamu, Keraton, Kantor Koeninglijk, dan Keraton R.A.T Tirtonegoro. Pada setiap pembabakan bangunan disebutkan benda-benda museum yang digunakan pada kegiatan Kerajaan dan menjadi budaya Sumenep. Benda peninggalan disusun secara alfabetis pada tiap bab. Untuk membuktikan bahwa konsep sudah sesuai untuk target sasaran, peneliti melakukan user testing pada stakeholder terkait.
\end{abstract}

Kata Kunci-katalog, museum Keraton Sumenep, identitas, budaya.

\section{PENDAHULUAN}

$\mathrm{K}$ ERATON Sumenep menjadi lokasi diadakannya Festival Keraton Nusantara dan Masyarakat Adat ASEAN (FKMA) V pada 2018, sebagai bentuk apresiasi dari Forum Silaturahmi Keraton Nusantara (FSKN) pada pemerintah Sumenep dalam pelestarian sejarah hingga berumur 750 tahun. Festival ini menarik pengunjung dari berbagai wilayah dan Negara yang tergabung dengan Forum Keraton ASEAN. Keraton Sumenep merupakan bangunan Keraton Nusantara terakhir di Jawa Timur yang masih berdiri dan digunakan,

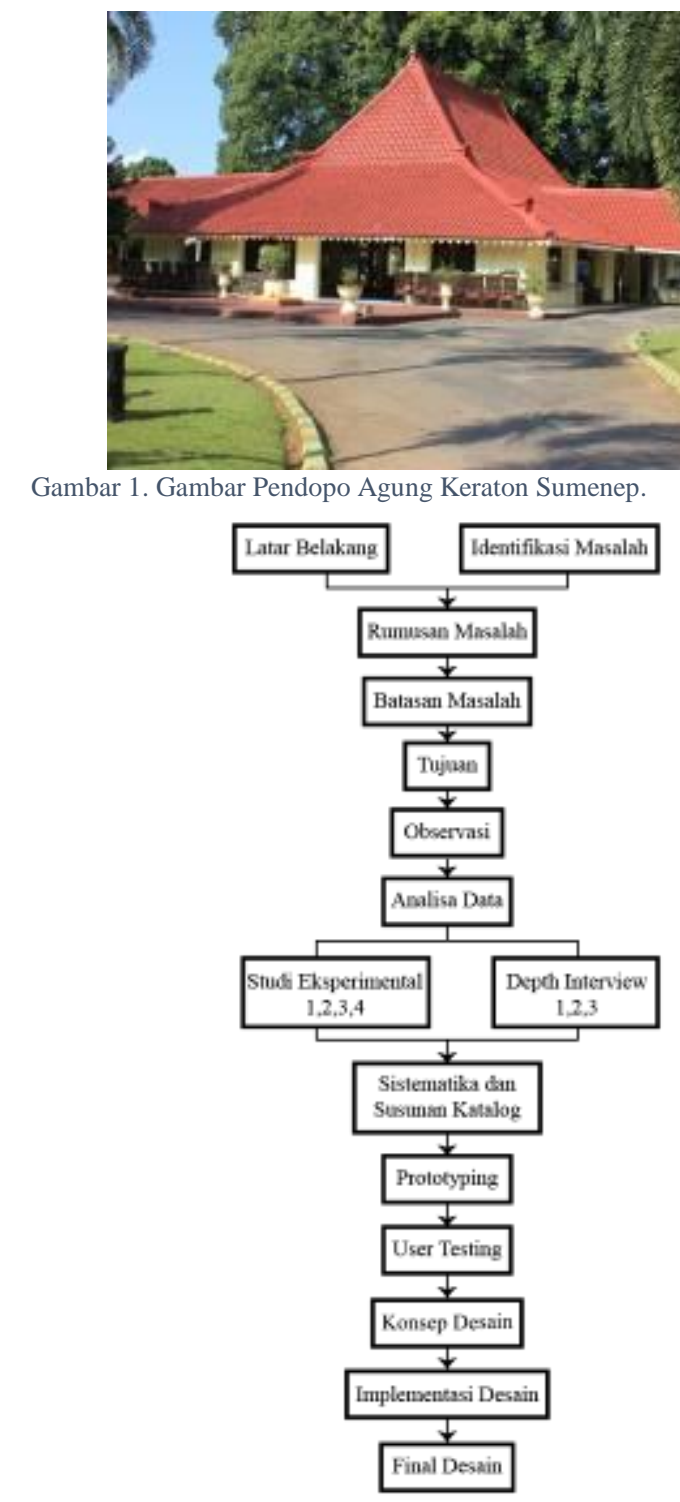

Gambar 2. Metodologi Penelitian.

salah satunnya digunakan sebagai balai pertemuan resmi dan sebagai museum. Museum Keraton Sumenep berisi benda bersejarah serta bangunan peninggalan Keraton Sumenep Pajagalan. Museum tersebut disahkan untuk melestarikan sejarah dan budaya Kraton Sumenep sejak masa pemerintahan Arya Wiraraja pada tahun 1269 M yang menjadi titik awal sejarah dan budaya Sumenep. Dari sejarah tersebut terdapat 


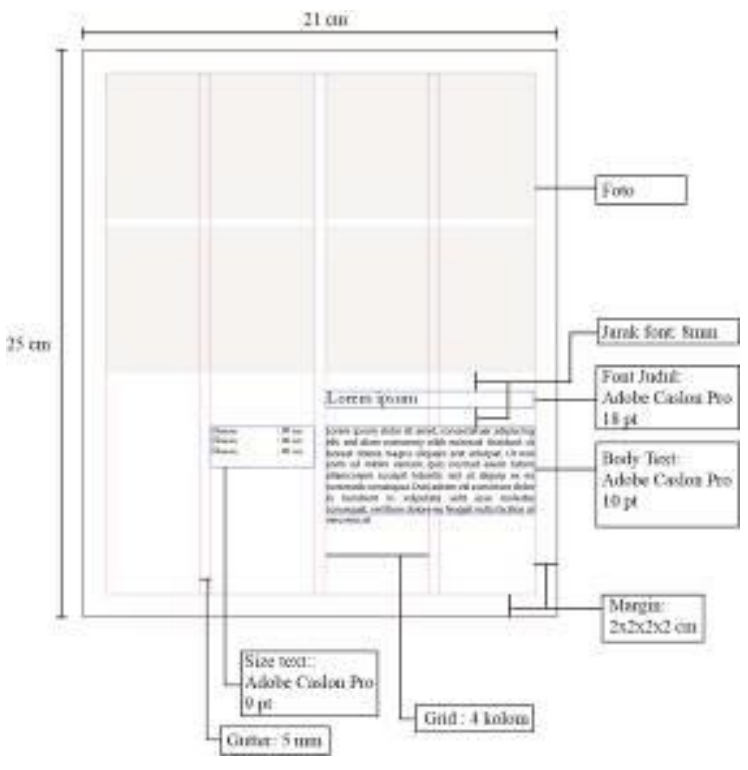

Gambar 3. Grid dan Layout Katalog.

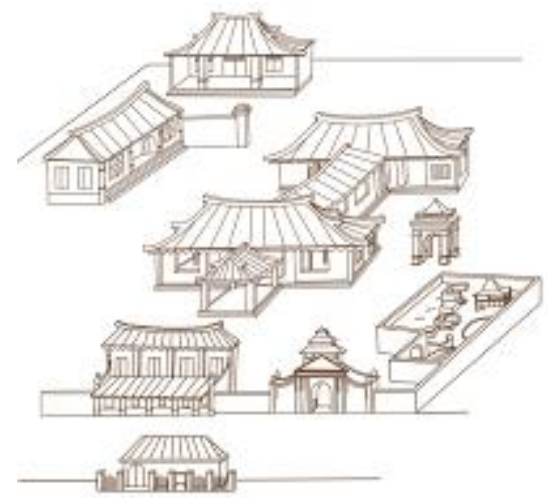

Gambar 4. Ilustrasi (rekonstruksi bangunan) dalam katalog.
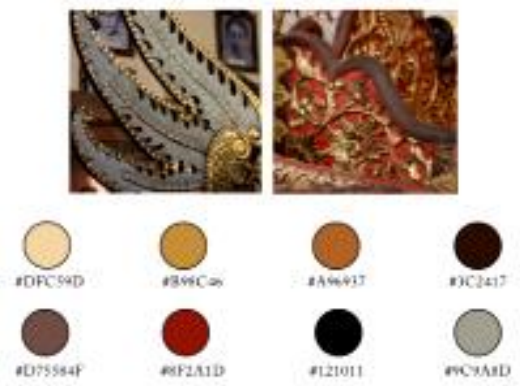

Gambar 5. Skema warna katalog.

budaya yang sampai saat ini masih dilakukan oleh masyarakat, sehingga Sumenep masih memiliki identitasnya sebagai masyarakat Keraton.

Selama ini sejarah dan budaya Sumenep dilestarikan melalui mulut ke mulut yang memiliki dampak pencampuran hingga terhentinya informasi di suatu masa. Sehubungan dengan hal tersebut, pelestarian perlu didokumentasikan pada suatu media. Museum pada umumnya menggunakan katalog sebagai acuan data maupun pengetahuan dasar tentang benda koleksi untuk pengunjung. Koleksi benda di Museum Keraton Sumenep memiliki cerita sejarah masing-masing yang menciptakan adat dalam masyarakat dan merupakan pondasi

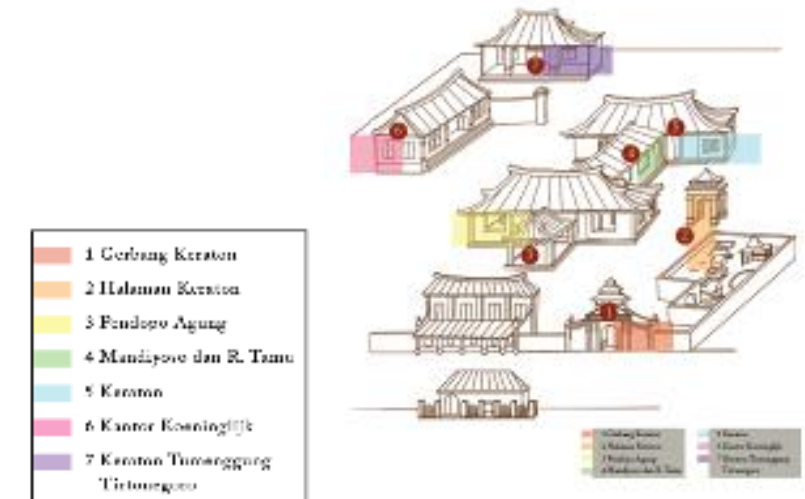

Gambar 6. Pewarnaan tiap bangunan.

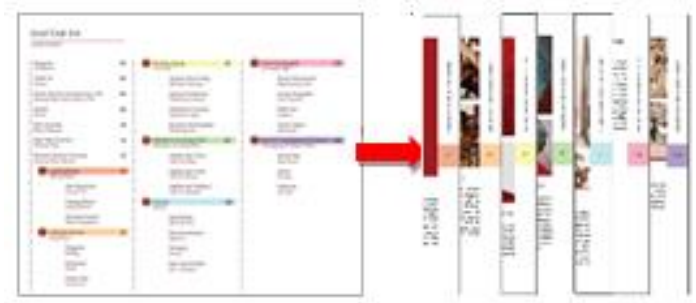

Gambar 7. Navigasi warna katalog tiap bab.

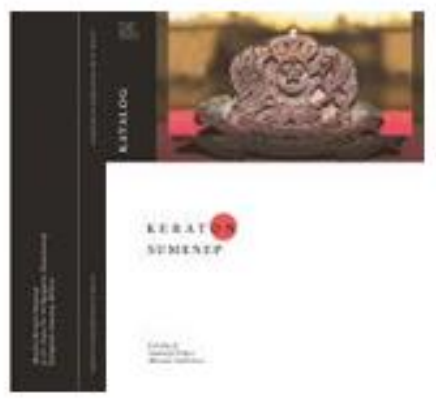

Gambar 8. Hasil akhir desain cover katalog Museum Keraton Sumenep.

masyarakat Sumenep dalam berbudaya. Katalog adalah daftar koleksi sebuah atau beberapa pusat dokumentasi yang disusun menurut sistem tertentu. Katalog museum berisi kumpulan data benda yang bersifat dinamis berdasarkan informasi dan penemuan lain yang berkembang.

Katalogisasi membantu dalam penyusunan sejarah Keraton Sumenep melalui cerita di balik data benda peninggalan dengan melibatkan foto benda, informasi, detail dan sistem informasi untuk mempermudah masyarakat dalam menemukan informasi. Perancangan katalog museum Keraton Sumenep ini diharapkan dapat menjadi salah satu cara untuk merepresentasikan identitas Sumenep sebagai masyarakat Keraton berdasarkan budaya yang tersirat dari benda peninggalan pada museum. Dengan perancangan ini, acuan informasi yang disebarkan melalui mulut ke mulut dapat divalidasi dalam sebuah katalog.

\section{URAIAN PENELITIAN}

\section{A. Lokasi Penelitian}

Penelitian ini dilakukan di Museum Keraton Sumenep yang berada di Jl. Dr. Sutomo No.6, Lingkungan Delama, 


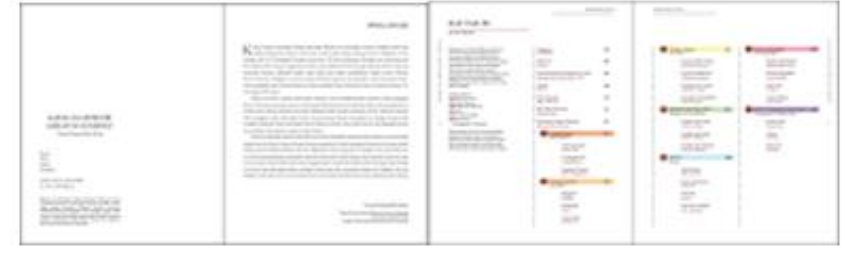

Gambar 9. Hasil desain halaman preliminaries.

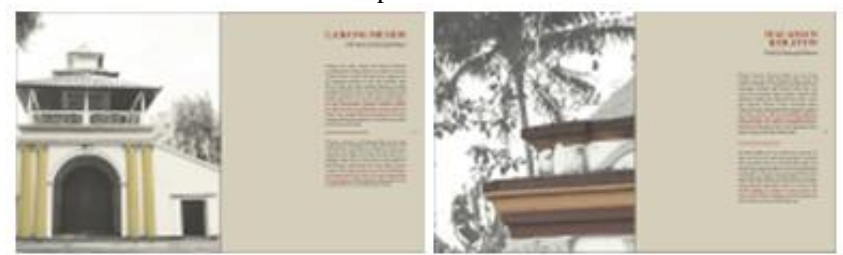

Gambar 10. Desain akhir divider antar bab.

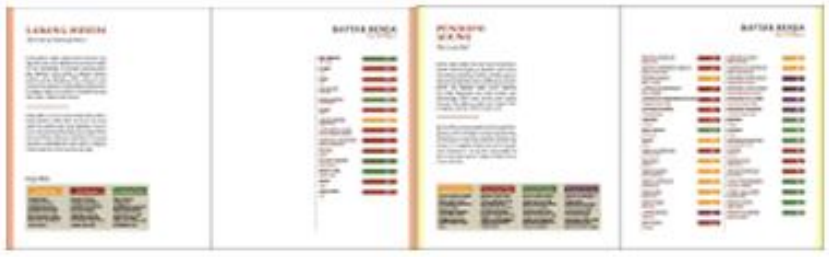

Gambar 11. Desain akhir daftar benda tiap bab.

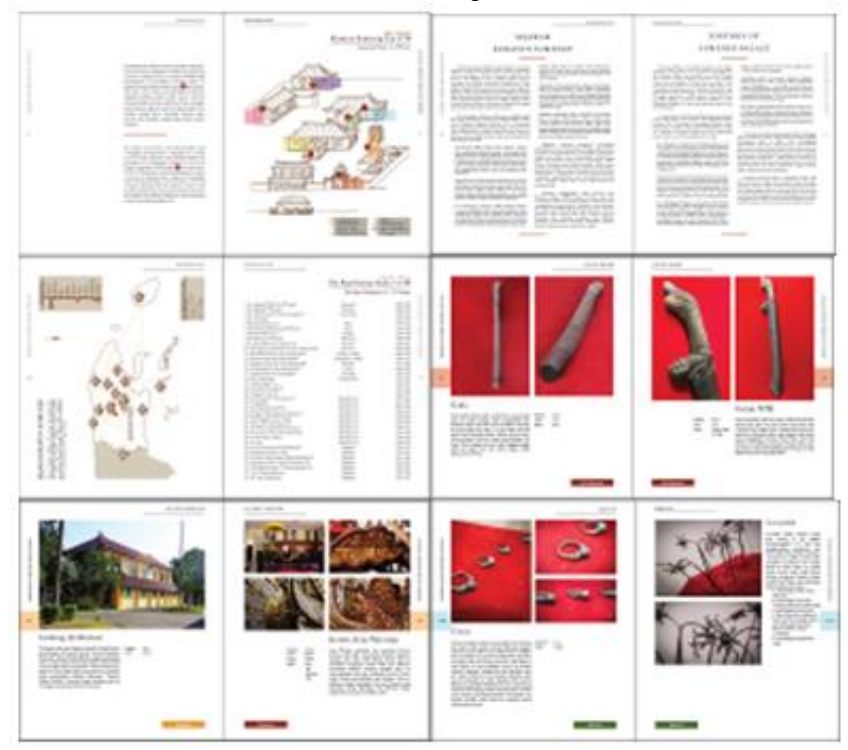

Gambar 12. Hasil akhir desain halaman isi.

Pajagalan, Kotasumenep, Kabupaten Sumenep. Berikut merupakan gambar dari lokasi yang akan digunakan untuk penelitian yang dapat dilihat pada Gambar 1. Peneliti akan melakukan perancangan katalog yang mencakup bendda-benda yang ada di museum, terdiri dari 3 pembagian museum yaitu:

1) Museum I (Gedung Bekas Gudang Senjata)

2) Museum II (Kantor Koeninglijk)

3) Museum III (Keraton R.A Tirtonegoro)

\section{B. Studi Literatur}

\section{1) Katalog}

Katalog adalah daftar koleksi sebuah pusat dokumentasi atau beberapa pusat dokumentasi yang disusun menurut sistem tertentu[1]. Salah satu fungsi katalog adalah sebagai media informasi dari sekumpulan koleksi dan mempermudah pengguna dalam mencari sebuah koleksi, Bentuk katalog beragam sesuai kegunaan dan kebutuhannya, yaitu katalog

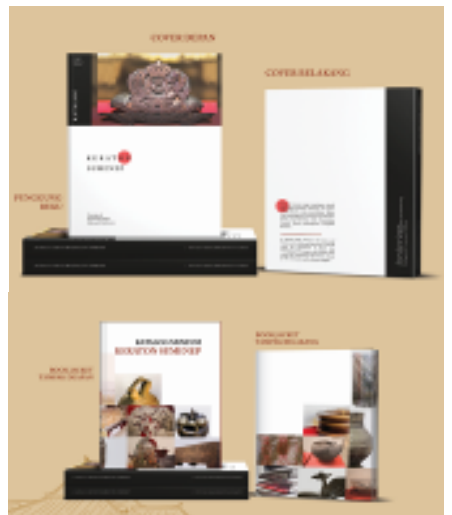

Gambar 13. Hasil akhir desain packaging katalog.

buku, kartu, lembaran, arsip, dan online. Katalog memiliki kerangka seperti buku pada umumnya, yaitu pembuka, isi, dan penutup. Perbedaannya terdapat pada isi katalog yang berupa susunan, sistem, dan konten lainnya yang tersusun secara berurutan dan teratur.

\section{2) Layout}

Layout adalah tata letak elemen-elemen desain terhadap suatu bidang dalam media tertentu untuk mendukung konsep/desain yang akan disampaikan[2]. Prinsip layout yang digunakan adalah sequence, emphasis, balance, unity.

\section{3) Grid}

Sistem grid digunakan untuk mensistematisasikan sebuah susunan konten agar dapat seimbang dalam sebuah halaman sehingga dapat bernilai obyektif. Grid adalah alat bantu dalam mengatur layout. Tata letak dan grid adalah alat paling dasar dan penting untuk menempatkan informasi dalam hirarki, kelompok atau kolom[3].

\section{4) Fotografi}

Fotografi adalah proses menggambar dengan menggunakan media cahaya yang menghasilakn foto dari suatu objek dengan merekam pantulan cahaya yang mengenai objek tersebut pada media yang peka cahaya. Jenis fotografi yang digunakan adalah fotografi produk dan bangunan.

\section{5) Tipografi}

Tipografi memegang peranan sangat penting dalam keberhasilan suatu karya desain grafis, baik sebagai unsur utama atau pelengkap[4]. Faktor penting dalam tipografi antara lain (1) legibility, (2) readibility, (3) visibility, (4) clearity.

\section{6) Sumber Konten}

\section{a. Buku Babad Modern Sumenep [5]}

Buku "Babad Modern Sumenep, Sebuah Telaah Historipgrafi" menjelaskan hal-hal tentang sejarah berdirinya Keraton Sumenep yang diiringi dengan pembahasan keragaman budaya dan peninggalan sejarah, serta hubungan dengan Negara lain. Buku ini menyajikan tentang politik dan budaya Sumenep dari masa awal dibangunnya hingga akhir sebagai pengenalan budaya dari sejarah.

\section{b. Buku Lintasan Sejarah Madura[6]}

Buku "Lintasan Sejarah Madura" memuat sejarah Madura secara menyeluruh dari awal mula ditemukannya pulau Madura dengan pembabakan zaman yang menjelaskan tentang 
relasi dengan Kerajaan dan Negara lain. Buku ini menyajikan informasi mengenai kedudukan penjajah di Pulau Madura sebagai bagian dari sejarah.

\section{Metodologi Penelitian}

Adapun tahapan kegiatan yang dilakukan saat penelitian dapat dilihat pada Gambar 2.

\section{Metode Pengumpulan Data}

1) Data Primer

a. Observasi

Observasi dilakukan oleh peneliti secara berkala selama 6 bulan untuk menggali konten katalog. Penulis melakukan observasi di beberapa lokasi terkait museum. Data yang didapatkan berupa daftar konten katalog yang terdiri dari foto, informasi, dan detail benda.

b. Studi Eksperimental

Studi Eksperimental (SE) dilakukan penulis untuk melengkapi konten katalog. SE pertama dilakukan untuk membuat draft buku yang berisi informasi benda-benda yang diteliti untuk konten katalog. Draft katalog mengandung foto benda, sejarah, dan stilasi bangunan Keraton Sumenep sebagai elemen desain. Hasil dari SE ini menjadi bahan utama penyusunan sistematika katalog.

c. Depth Interview

Wawancara dan diskusi dilakukan kepada beberapa narasumber untuk merangkai konten.

1. Ahli sejarah Sumenep Jakfar Farouk A., S.H. adalah narasumber utama dalam penelitian ini. Diskusi dilakukan dalam mengevaluasi draft yang dibuat penulis untuk mencapai kebenaran informasi. Kegiatan ini dilakukan secara berkala dan berulang pada setiap pembaruan draft hingga menjadi sebuah buku katalog. Pembenaran konten dilakukan bersama dengan narasumber dengan tambahan dari sejarawan dan budayawan Sumenep lainnya.

2. M. Tadjul Arifien dan Syaf. Anton W.R. seorang sejarawan dan budayawan Sumenep. Wawancara ini dilakukan untuk melengkapi konten katalog karena informasi tertulis mengenai sejarah ini masih minim.

3. Ahli editorial design dari Akronim Studio Surabaya Adji Herdanto, S.T. Kegiatan ini bertujuan untuk mengolah informasi yang didapatkan menjadi sebuah susunan katalog yang sistematis. Diskusi dilakukan secara berkala dan berulang beriringan dengan Studi Eksperimental menggunakan trial and error. Pada kegiatan ini juga didiskusikan mengenai teknik dalam melakukan fotografi benda peninggalan di museum Keraton Sumenep.

4. Disbudparpora Sumenep dan pihak museum Keraton Sumenep adalah salah satu narasumber yang memfasilitasi penelitian dengan memberikan data benda tertulis. Data yang diberikan berupa file data cagar budaya 2015, berisi benda-benda peninggalan Keraton Sumenep. Wawancara ini membahas mengenai prospek dari hasil penelitian untuk museum Keraton Sumenep.

\section{2) Data Sekunder}

Data sekunder digunakan sebagai data pembanding untuk melengkapi konten buku, antara lain: a. Buku sumber yang membahas tentang sejarah dan budaya Keraton Sumenep.

b. Data yang didapat dari internet berupa artikel, berita, dan dokumentasi foto tentang Keraton Sumenep.

c. Produk pembanding yang berhubungan dengan konten maupun teknis yang digunakan dalam katalog.

\section{HASIL DAN DISKUSI}

\section{A. Konsep Luaran}

Berdasarkan analisa yang dilakukan, peneliti mendapatkan 4 kata kunci yang menjadi dasar pengembangan katalog Museum Keraton Sumenep yaitu Katalog, Museum Keraton Sumenep, Budaya, dan Identitas. Konten yang dihasilkan dalam katalog bersifat edukatif dan persuasif. Katalog harus sistematis dengan prinsip penyusunan sesuai dengan kebutuhan informasi target masyarakat pada masa produktif dan menyukai sejarah budaya. Identitas Keraton Sumenep harus ditampilkan pada setiap bagian katalog sehingga terjadi repetisi bahwa Sumenep adalah daerah Keraton.

Dengan menyajikan informasi yang sistematis akan mempermudah pembaca mendapatkan informasi yang diinginkan. Dari hal tersebut, katalog Museum Keraton Sumenep tidak hanya menyusun katalog dengan informasi benda tapi juga mengelompokkan benda-benda tersebut pada kategori tertentu. Kumpulan kategori tersebut dikelompokkan kembali menjadi 7 pembabakan yang menggunakan lokasi terjadinya sejarah dan budaya Keraton Sumenep pada jaman kerajaan. Bahasa yang digunakan merupakan Bahasa Indonesia baku dengan terjemahan Bahasa Inggris pada tiap section. Bahasa Madura klasik juga tetap digunakan pada katalog namun tidak menyeluruh sebagai kesan otentik. Elemen visual yang digunakan berperan sebagai penjelas dan bagian dari sistem penyusunan katalog.

Konsep katalog ditampilkan pada desain layout yang minimalis. Konten yang ditampilkan bersifat tradisional merupakan bentuk penyajian identitas Sumenep sebagai daerah Keraton yang telah berdiri selama ratusan tahun. Agar tidak menghilangkan unsur sejarah dan budaya, maka desain yang modern akan dipadukan dengan istilah berbahasa Madura pada nama benda. Ketiga hal tersebut disimpulkan menjadi sebuah big idea yaitu "Budaya Lahir Melalui Sejarah" yang berarti sejarah adalah asal terciptanya budaya.

\section{B. Konten Buku}

Struktur dan konten untuk Katalog Museum Keraton Sumenep terdiri dari bagian pendahuluan dan penyajian benda museum dengan 7 pembabakan menurut lokasi terjadinya sejarah. Konten dipilih berdasarkan hasil penelitian, antara lain:

1. Cover (depan, belakang dan punggung buku)

2. Halaman judul

3. Copyright

4. Halaman kata pengantar

5. Daftar Isi

6. Pendahuluan 
a. Denah Keraton Sumenep Era 1750

b. Sejarah

c. Peta Sumenep

d. Raja-Raja Sumenep

7. Museum Keraton Sumenep

a. Bab 1 - Labang Mesem

b. Bab 2 - Halaman Keraton

c. Bab 3 - Pendopo Agung

d. Bab 4 - Mandiyoso \& Ruang Tamu

e. Bab 5 - Keraton

f. Bab 6 - Kantor Koeninglijk

g. Bab 7 - Keraton R.A. Tirtonegoro

8. Tentang Penulis

\section{Grid dan Layout}

Katalog ini dilayout dengan menggunakan bantuan grid kolom. Elemen penyusun layout dalam buku terdiri dari judul, body text, caption (keterangan detail gambar), sistem warna, footer (identitas dan numbering), dan gambar. Layout lebih jelas dapat dilihat pada Gambar 3.

\section{Gaya Bahasa}

Gaya bahasa yang digunakan dalam penyampaian informasi dalam katalog ini menggunakan kalimat naratif dan deskriptif. Kalimat naratif bersifat menceritakan suatu peristiwa atau suatu kisah. Sedangkan kalimat deskriptif lebih menggambarkan wujud suatu objek.

\section{E. Fotografi}

Jenis fotografi yang digunakan dalam perancangan ini adalah fotografi produk dan bangunan Fotografi produk digunakan untuk menangkap gambar benda dari beberapa sisi sehingga menjadi focus utama pada halaman. Fotografi bangunan digunakan untuk menggambarkan sebuah lokasi pada Keraton Sumenep. Kriteria untuk foto pada katalog adalah tone warna hangat, kontras dan ketajaman tinggi, tiap benda memiliki minimum 2 foto dan maksimum 4 foto. Kriteria desain tersebut mewakili struktur dan detail benda.

\section{F. Tipografi}

Buku ini menggunakan font Adobe Caslon sebagai font utama untuk judul, subjudul, dan body text. Pemilihan font Adobe Caslon dikarenakan font serif ini memiliki kesan elegan dan modern. Font Fanklin Gothic digunakan sebagai font minor untuk mengisi bagian caption foto dan keterangan tambahan.

\section{G. Ilustrasi (Rekonstruksi Bangunan)}

Ilustrasi merupakan elemen visual untuk menggambarkan hal yang tidak bisa disampaikan melalui fotografi. Dalam katalog, ilustrasi digunakan pada bagian awal buku sebagai penjelas denah dan peta Sumenep. Ilustrasi dibuat dengan outline tebal dengan tinta pena warna coklat seperti pada Gambar 4.

\section{H. Skema Warna}

Warna yang mendominasi katalog adalah warna putih, hitam, dan merah marun. Warna lain perancangan ini adalah mengikuti tema yang diangkat yaitu Sejarah Keraton Sumenep. Dari tema tersebut, penulis menentukan untuk menggunakan warna pada Kereta Arya Wiraraja dimana beliau adalah pendiri dari Keraton Sumenep yang dapat dilihat pada Gambar 5.

\section{Sistematika Katalog}

Katalog Museum disusun dengan dibagi menjadi 7 bab mengikuti alur masuk yaitu dari gerbang keraton hingga bangunan terdalam yaitu Keraton Tumenggung Tirtonegoro. Alur katalog diterapkan dengan pembedaan warna pada setiap bab. Pewarnaan dapat dilihat pada Gambar 6.

Setiap bab dirancang untuk memiliki kode warnanya sendiri sehingga menjadi nagivasi yang mudah disamping pemberian nomor halaman. Navigasi warna yang digunakan dapat dilihat pada Gambar 7.

Pengkategorian benda berada pada tiap awal bab yang Pengkategorian benda berada pada tiap awal bab yang berisi daftar benda yang akan ditampilkan pada bab tersebut. Tiap kategori memiliki warna yang berbeda dan akan muncul sebagai label pada tiap halaman benda yang disusun alfabetis.

\section{J. Teknis Katalog}

1. Ukuran : $21 \mathrm{~cm} \mathrm{x} 25 \mathrm{~cm}$

2. Jumlah halaman : 160 halaman

3. Penggunaan warna : full color

4. Jenis kertas isi : HVS 100 gsm

5. Cover : Soft cover dan Hard cover

7. Packaging : Book jacket (untuk hard cover)

\section{IMPLEMENTASI DESAIN}

Hasil desain berupa konten teks, foto, dan ilustrasi yang diimplementasikan dalam buku yang berjudul "Katalog Museum Keraton Sumenep".

\section{A. Hasil akhir desain cover}

Foto logo Keraton Sumenep dalam stempel yang digunakan pada pemerintahan Sultan Abdurrahman menandakan identitas keraton sebagai pemerintahan di Sumenep yang berbudaya dan menjadi sejarah nasional seperti pada Gambar 8.

\section{B. Hasil akhir desain halaman preliminaries}

Halaman terdiri dari halaman copyright, daftar isi, dan kata pengantar. Pada halaman preliminaries terdapat beberapa foto yang mewakili foto di halaman isi buku dapat dilihat pada gambar 9.

\section{Hasil akhir desain halaman pemisah bab}

Halaman divider bab terdapat foto di halaman bagian kiri dengan format portrait full halaman dengan editing low saturation dan highlight pada bagian khasnya. Pada halaman bagian kanan terdapat judul bab dan penjelasan singkat mengenai isi dari bab. Pada bagian belakang divider terdapat daftar benda yang diurutkan secara alfabetis sehingga menjadi gambaran awal akan isi bab yang lebih lanjut dan pembaca dapat memilih informasi lebih mudah dapat dilihat pada Gambar $10-11$. 


\section{Hasil akhir desain halaman isi}

Berikut ini beberapa layout yang mewakili halaman isi katalog dapat dilihat pada Gambar 12.

\section{E. Hasil akhir desain packaging katalog}

Packaging diterapkan pada katalog versi hard cover berbentuk book jacket dengan bahan Art Paper 260 gsm agar tidak mudah rusak. Cover pada packaging dibuat berbeda dengan cover buku, agar tidak terjadi pengulangan visual. Sedangkan versi soft cover tidak menggunakan packaging. Berikut implementasi desain akhir hard cover dengan book jacket pada katalog Museum Keraton Sumenep dapat dilihat pada Gambar 13.

\section{KESIMPULAN}

Konsep "Budaya Lahir Melalui Sejarah" dipilih karena peneliti ingin menciptakan informasi sekaligus pelestarian sejarah dan budaya mengenai Keraton Sumenep sebagai Keraton Nusantara berusia ratusan tahun yang telah diakui oleh ASEAN, juga untuk merepresentasikan identitas budaya Sumenep sebagai daerah Keraton. Identitas budaya ditampilkan pada sejarah tiap benda peninggalan serta penggunaannya pada budaya Kerajaan masa lampau.

Kemudian setelah peneliti selesai mendesain media, peneliti melakukan sebuah user testing kepada stakeholder dan beberapa responden sebagai sample. User testing ini dilakukan untuk membuktikan bahwa hasil konsep desain dari peneliti sudah sesuai dan dapat membantu menyelesaikan permasalahan yang ada. Sehingga tujuan peneliti dalam merepresentasikan identitas budaya Sumenep sebagai daerah Keraton telah tercapai.

\section{UCAPAN TERIMA KASIH}

Penulis menyampaikan terimakasih pada Disbudparpora Sumenep, Pihak Museum Keraton Sumenep, Sejarawan Sumenep, Departemen DKV ITS, serta semua pihak yang telah membantu perancangan ini.

\section{DAFTAR PUSTAKA}

[1] S. Basuki, Pengantar Dokumentasi. Bandung: Rekayasa Sains, 2004.

[2] R. S, Layout Dasar dan Penerapannya. Jakarta: Gramedia Pustaka Utama, 2009.

[3] A. Graver and B. Jura, Best Practices for Graphic Designers, Grids and Page Layouts: An Essential Guide for Understanding and Applying Page Design Principles, 36660th Ed. Beverly, Massachusetts: Rockport Publishers, 2012.

[4] D. Sihombing and W. Sunarto, Tipografi dalam Desain Grafis. Gramedia Pustaka Utama, 2001.

[5] Z. Ahmad, Babad Modern Sumenep: Sebuah Telaah Historiografi. Yogyakarta: Araska Publisher, 2018.

[6] T. Arifin, "Sumenep dalam lintasan sejarah arifin," Sumenep, 2012. 